Marquette University

e-Publications@Marquette

\title{
Positive and Negative Sources of Emotional Arousal Enhance Long-Term Word-List Retention When Induced as Long as 30 Min After Learning
}

Kristy A. Nielson

Marquette University, kristy.nielson@marquette.edu

Mark R. Powless

Marquette University

NOTICE: this is the author's version of a work that was accepted for publication in Neurobiology of Learning and Memory. Changes resulting from the publishing process, such as peer review, editing, corrections, structural formatting, and other quality control mechanisms may not be reflected in this document. Changes may have been made to this work since it was submitted for publication. A definitive version was subsequently published in Neurobiology of Learning and Memory, Vol. 88, No. 1 (July 2007): 40-47. DOI. C Elsevier 2007. Used with permission. 
NOT THE PUBLISHED VERSION; this is the author's final, peer-reviewed manuscript. The published version may be accessed by following the link in the citation at the bottom of the page.

\title{
Positive and negative sources of emotional arousal enhance long- term word-list retention when induced as long as 30 min after learning
}

\author{
Kristy A. Nielson \\ Department of Psychology, Marquette University, \\ Milwaukee, WI \\ Integrative Neuroscience Research Center, Marquette University, \\ Milwaukee, WI \\ Foley Center for Aging and Development, Departments of \\ Neurology and Psychiatry and Behavioral Medicine, and the \\ Functional Neuroimaging Research Center, Medical College of \\ Wisconsin, Milwaukee, WI \\ Mark Powless \\ Department of Psychology, Marquette University, \\ Milwaukee, WI
}

\begin{abstract}
The consolidation of newly formed memories occurs slowly, allowing memories to be altered by experience for some time after their formation. Various treatments, including arousal, can modulate memory consolidation when given soon after learning, but the degree of time-dependency of these
\end{abstract}


NOT THE PUBLISHED VERSION; this is the author's final, peer-reviewed manuscript. The published version may be accessed by following the link in the citation at the bottom of the page.

treatments in humans has not been studied. Thus, 212 participants learned a word list, which was followed by either a positively or negatively valenced arousing video clip (i.e., comedy or surgery, respectively) after delays of 0 , 10, 30 or $45 \mathrm{~min}$. Arousal of either valence induced up to $30 \mathrm{~min}$ after learning, but not after $45 \mathrm{~min}$, significantly enhanced one-week retrieval. The findings support ( 1 ) the time-dependency of memory modulation in humans and (2) other studies that suggest that it is the degree of arousal, rather than valence that modulates memory. Important implications for developing memory intervention strategies and for preserving and validating witness testimony are discussed.

Keywords: Memory consolidation, Memory modulation, Time-dependent facilitation, Emotion, Arousal, Eyewitness accuracy, Valence, Intervention, Enhancement

\section{I ntroduction}

Emotional and arousing events are recollected with greater frequency than similar but neutral events, which is likely an adaptive function, effectively highlighting important stimuli and events to protect and prepare an organism for similar future occasions (McGaugh, 2000). Memory consolidation, believed to underlie this highlighting process, is the outcome of a complex set of neurobiological processes occurring after the initial formation of a memory (McGaugh, 2000; Müller \& Pilzecker, 1900; Revelle \& Loftus, 1992; Torras-Garcia, Portell-Cortes, Costa-Miserachs, \& MorgadoBernal, 1997). Thus, events occurring after learning can modulate memory consolidation.

A variety of substances, including glucose and the adrenal hormones epinephrine and norepinephrine, are released into the bloodstream during times of arousal, stress and emotion and indirectly alter brain stem and amygdalar function (Gold, 2005; Hamann, 2001; McGaugh, 2000; McGaugh, Cahill, \& Roozendaal, 1996). When administered soon after learning, these substances alter memory with the classic "inverted-U" dose response effect that has been shown for other aspects of performance (McGaugh, 2000; Yerkes \& Dodson, 1908). Although the efficacy of these post-training treatments varies with multiple factors, such as dose or intensity of treatment, their efficacy also typically diminishes with time such that they are most effective when given shortly after learning (cf. McGaugh, 1989, 2000).

[Neurobiology of Learning and Memory, Vol 88, No. 1 (July 2007): pg. 40-47. DOI. This article is (C) Elsevier and permission has been granted for this version to appear in e-Publications@Marquette. Elsevier does not grant permission for this article to be further copied/distributed or hosted elsewhere without the express permission from Elsevier.] 
The vast majority of human studies examining the effects of arousal on learning or memory have used inherently emotional materials or interventions before or coincident with the learning task. As such, it is impossible to decipher in these studies whether the effect is on attention, encoding, consolidation or some combination of these phases. However, several recent studies have demonstrated memory modulatory effects in human participants by comparable mechanisms of action as have been shown in rodent studies using various posttraining treatments including norepinephrine (Southwick et al., 2002), glucose (Manning, Parsons, \& Gold, 1992), nicotine (Colrain, Mangan, Pellett, \& Bates, 1992), and non-invasive treatments such as muscle tension (Nielson \& J ensen, 1994; Nielson, Radtke, \& Jensen, 1996), stress (Cahill, Gorski, \& Le, 2003) and negative and positive emotional arousal (Nielson \& Bryant, 2005; Nielson, Yee, \& Erickson, 2005). Importantly, no human study has yet examined the time-dependency of these effects; no study has varied the delay of the intervention after learning. Furthermore, no human study has compared the effects of positively and negatively valenced stimuli within the same paradigm.

The purpose of the present study was to evaluate the time dependency of modulating memory consolidation in humans. We employed a word-list learning task that was followed by a positively or negatively valenced arousal stimulus after delays of $0,10,30$ and $45 \mathrm{~min}$. Control participants experienced no stimulus after learning. Because human studies with delayed interventions have not been done, it was difficult to hypothesize which treatments would be effective. Based on the human literature, the immediate condition of either valence was expected to be effective and although the animal literature varies it suggests that systemic treatments given soon after learning are most effective (cf. McGaugh, 1989, 2000). Thus, it was hypothesized that arousal of either valence occurring at either 0 or 10 min after learning would enhance retention measured one week later; it was less predictable whether longer delays would be effective.

\section{Experiment 1}

Experiment 1 was conducted to identify a positively valenced arousal stimulus for use in the primary experiment. In previous studies, negative arousal sources, such as accident or surgical scenes

[Neurobiology of Learning and Memory, Vol 88, No. 1 (July 2007): pg. 40-47. DOI. This article is (C) Elsevier and permission has been granted for this version to appear in e-Publications@Marquette. Elsevier does not grant permission for this article to be further copied/distributed or hosted elsewhere without the express permission from Elsevier.] 
have often been used in research in part because subjective responses to such stimuli are relatively consistent across participants. In contrast, responses to positive arousal sources, such as comedy, are more variable across participants. In order to identify a comedic arousal source that would have relatively universal affective appeal, a variety of comedy video clips were assessed for suitability. Twenty clips suggested by the authors and research assistants were preliminarily viewed as potential arousal sources for a memory modulation study. From these, five were selected for pilot testing.

\subsection{Methods}

\subsubsection{Participants}

Forty-two undergraduate students ( 33 female, 9 male; mean age $=18.81, \mathrm{SD}=.86$ ) were included in this study and received course credit for their participation. Procedures were reviewed and approved by the Internal Review Board.

\subsubsection{Materials}

Five video clips were evaluated by each participant: (1) "Saturday Night Live (SNL)" J ingleheimer Junction (4 min); (2) "Even Stephens" skit (4 min, $10 \mathrm{~s}$ ); (3) "Spaceballs" scene (50 s); (4) "Adult Swim's" Spaceghost scene (11 min, $30 \mathrm{~s}$ ); (5) "SNL" Behind the Music, Blue Oyster Cult skit ( $5 \mathrm{~min}, 45 \mathrm{~s}$ ). Two questions were posed after each clip about current arousal and mood state and eight questions were posed about the clips themselves (attempting to evaluate both cognitive and affective components of the humor response) (Gavanski, 1986). Each question was posed on a 10-point Likert-type scale ( 1 = not at all, 10 = extremely): (1) current mood; (2) current arousal; (3) funny; (4) smile; (5) laugh; (6) witty; (7) funny to others; (8) ridiculous. Participants were also asked to indicate which clip was their favorite.

\subsubsection{Results}

The results are presented in Table 1 . The favorite clip, chosen by $43.9 \%$ of participants was SNL J ingleheimer J unction $\left(X^{2}(4)=20.1\right.$, $p=.001)$, with "SNL" Behind the Music second highest (23.8\%).

[Neurobiology of Learning and Memory, Vol 88, No. 1 (July 2007): pg. 40-47. DOI. This article is @ Elsevier and permission has been granted for this version to appear in e-Publications@Marquette. Elsevier does not grant permission for this article to be further copied/distributed or hosted elsewhere without the express permission from Elsevier.] 
These two clips and the "Even Stephens" clip were consistently highly rated for mood, arousal and humor across the various questions asked. It appeared that any of the three clips would be effective for producing arousal, but the clip also chosen as favorite most consistently ("SNL" J ingleheimer Junction) was selected for use in the primary experiment.

Table 1. Results of arousal stimulus pilot testing-evaluation of five film clips showing favorite clip (\%) and median ratings (scale of 1-10) for several cognitive and affective humor categories by 42 participants

\section{SNL'S J ingleheimer Stephens" J unction skit \\ "Even skit}

\section{"Spaceballs" Adult Swim's scene \\ "Spaceghost" skit}

SNL'S

Behind

the

Music:

Blue

Oyster

Cult

\begin{tabular}{|c|c|c|c|c|c|}
\hline $\begin{array}{l}\text { Favorite clip } \\
(\%) \\
X^{2}(4)=20.1 \\
p=.001\end{array}$ & 43.9 & 19.5 & 7.3 & 4.9 & 24.4 \\
\hline Mood & 8.0 & 7.0 & 7.0 & 5.0 & 7.0 \\
\hline Aroused & 7.0 & 7.0 & 6.0 & 4.0 & 6.0 \\
\hline Funny & 8.0 & 7.0 & 5.0 & 1.0 & 7.0 \\
\hline Smile & 8.0 & 7.0 & 6.0 & 2.0 & 8.0 \\
\hline Laugh & 7.0 & 6.0 & 3.5 & 1.0 & 6.0 \\
\hline Witty & 7.0 & 6.0 & 4.0 & 2.0 & 6.0 \\
\hline $\begin{array}{l}\text { Funny to } \\
\text { others }\end{array}$ & 8.0 & 7.0 & 6.5 & 3.0 & 7.0 \\
\hline Ridiculous & 7.0 & 6.5 & 6.5 & 10.0 & 6.0 \\
\hline
\end{tabular}

\section{Experiment 2}

\subsection{Methods}

\subsubsection{Participants}

Two hundred and twelve undergraduate students (155 female, 57 male) were included in this experiment and received course credit for their participation. Procedures were reviewed and approved by the Institutional Review Board. Quasi-random assignment was made to group experimental conditions upon entrance to the room. Several sessions were used to achieve adequate cell populations, but all 
conditions were represented at each session with no less than seven participants per condition at any time. Five groups were used: Control ( no arousal; $n=47$ ), Immediate ( $n=48 ; 32$ positive, 16 negative), 10-min delay ( $\mathrm{n}=39 ; 24$ positive, 15 negative), 30-min delay ( $n=38 ; 24$ positive, 14 negative) and 45-min delay $(n=40 ; 24$ positive, 16 negative).

\subsubsection{Materials}

Thirty nouns were recorded onto videotape using white letters on a dark blue background and presented at 2-s intervals. To equate memorableness, each word was highly imaginable ( $>6.0$ on a scale of 1-7; Paivio, Yuille, \& Madigan, 1968) and 19 of the 30 words had standardized arousal and valence values, showing them as a group to be of low to moderate arousal and moderate valence ( 9 pt scale, arousal $M=4.65, S D=0.8$; valence $M=5.91, S D=1.6)$. The averages were comparable to the overall normative dataset from which they were taken (Bradley \& Lang, 1999).

The arousal conditions were manipulated using videotaped liveaction oral surgery (negative arousal), which was demonstrated in previous studies to produce subjective and physiological arousal (Nielson et al., 2005; Stone \& Nielson, 2001), or comedy using the "SNL" J ingleheimer J unction skit (positive arousal; see Experiment 1).

Immediate free recall (prior to the arousal manipulation) and one-week recognition tests were used to assess memory for the word list. The recognition test consisted of 140 words (the 30 list items and 110 distracter words, using the same criteria used for the target list), presented in 5 columns of 28 words each. The distracter items were selected using the same criteria as was used for targets. The large number of distracters was used to enhance task difficulty (Nielson \& Jensen, 1994). Participants were instructed to mark all words that they believed were from the original word list. Scores were corrected for guessing using the following formula: Corrected recognition $=(1-E R) *(\%$ Hits $)$, where \% Hits $=$ Hits $/ 30$ and Error Rate $(E R)=$ proportion of false alarms (FA/110).

[Neurobiology of Learning and Memory, Vol 88, No. 1 (July 2007): pg. 40-47. DOI. This article is @ Elsevier and permission has been granted for this version to appear in e-Publications@Marquette. Elsevier does not grant permission for this article to be further copied/distributed or hosted elsewhere without the express permission from Elsevier.] 
NOT THE PUBLISHED VERSION; this is the author's final, peer-reviewed manuscript. The published version may be accessed by following the link in the citation at the bottom of the page.

A variety of questionnaires and a reasoning test were administered (as filler during delay intervals). These surveys were not scored or analyzed for the present study.

\subsubsection{Procedures}

Upon arrival, each participant was given an explanation regarding the study's tasks and procedures and informed consent was obtained. Participants were informed that the study would involve testing their memory ability. The list of 30 nouns was presented via videotape one word at a time (one every $2 \mathrm{~s}$ ) and was followed immediately by a free recall test. Participants were instructed to silently repeat the words as they were presented. Control participants were then called out to a second room by participant number and dismissed. The remaining groups of participants were called out to the second room after the appropriate delay. While waiting, participants completed a packet of various surveys. Once seated in the second room, participants were instructed to watch a video clip that they would be asked to evaluate afterward. First, they completed a 10-pt Likert-type subjective mood state survey ( 1 , extremely negative to 10 , extremely positive) and a 10-pt Likert-type subjective arousal state survey ( 1 , not aroused at all to 10 , extremely aroused). They then viewed the 3-min videotaped stimulus, either negative or positive depending on group assignment, followed by again completing the arousal and mood state surveys as well as an opinion survey about the video clip. After returning one week later, participants completed the unannounced 140-item recognition test. Recognition scores were corrected for guessing. This was followed by questions about the purpose of the study and whether a memory test was expected. The remaining time was used to complete the questionnaire packet.

Debriefing was conducted and participants were thanked and released.

\subsubsection{Results}

All analyses were performed using Statistical Package for the Social Science (SPSS, Chicago, IL), ver. 13.0 for Windows using a $p<.05$ criterion for significance. Most participants in the Control condition were not asked to complete arousal or mood ratings, but as a manipulation check a sub-group of Controls $(n=18)$ completed baseline arousal and mood ratings. The demographic data, immediate

[Neurobiology of Learning and Memory, Vol 88, No. 1 (July 2007): pg. 40-47. DOI. This article is @ Elsevier and permission has been granted for this version to appear in e-Publications@Marquette. Elsevier does not grant permission for this article to be further copied/distributed or hosted elsewhere without the express permission from Elsevier.] 
recall scores and baseline mood and arousal ratings showed that the groups were not different prior to the arousal manipulation $(p>.05$; see Table 2). However, because short-term recall was correlated with delayed retrieval ( $r=.64)$, which is typical, it was used as a covariate in the subsequent memory analyses.

Table 2. Group demographics and immediate recall (mean ( \pm SEM))

\begin{tabular}{|c|c|c|c|c|c|}
\hline Group & Gender & Age (years) ${ }^{a}$ & $\begin{array}{c}\text { I mmediate } \\
\text { recall ( \% ; } \\
\text { pre-arousal) }\end{array}$ & $\begin{array}{c}\text { Baseline } \\
\text { mood (1- } \\
10)^{b}\end{array}$ & $\begin{array}{c}\text { Baseline } \\
\text { arousal (1- } \\
\text { 10) }^{\mathbf{b}}\end{array}$ \\
\hline ntrol & $11 \mathrm{M}, 36 \mathrm{~F}$ & $19.17(.13)$ & $46.67(2.04)$ & $7.2(.36)$ & $5.3(.49)$ \\
\hline nmediat & $13 \mathrm{M}, 35 \mathrm{~F}$ & $19.04(.16)$ & $49.72(1.52)$ & $7.4(.23)$ & \\
\hline & $10 \mathrm{M}, 29 \mathrm{~F}$ & $19.14(.16)$ & $49.32(2.04)$ & $6.8(.25)$ & $5.3(.34)$ \\
\hline & $9 \mathrm{M}, 29 \mathrm{~F}$ & $19.13(.18)$ & $47.63(1.93)$ & $6.9(.25)$ & $5.1(.34)$ \\
\hline & $14 \mathrm{M}, 26 \mathrm{~F}$ & $19.35(.24)$ & $46.75(2.15)$ & $7.1(.24)$ & $5.4(.33)$ \\
\hline & $\begin{array}{l}x^{2}(4)^{c}=1.8 \\
5, p>.76\end{array}$ & $\begin{array}{l}F(4,203)=0.5 \\
5, p>.70\end{array}$ & $\begin{array}{l}F(4,207)=0.4 \\
4, p>.78\end{array}$ & $\begin{array}{l}F(4,174)=0.9 \\
8, p>.42^{d}\end{array}$ & $\begin{array}{l}F(4,174)=0 . \\
0, p>.81^{d}\end{array}$ \\
\hline \multicolumn{6}{|c|}{$\begin{array}{l}\text { Total } \mathrm{N}=212 \text {. } \\
\text { Four participants (two in } 10-\mathrm{min} \text {, one in } 30-\mathrm{min} \text {, and one in control) did not report } \\
\text { age. } \\
\text { Four participants (two immediate, two in } 10-\mathrm{min} \text { ) failed to complete, and only a } \\
\text { ubset of Control participants were administered the baseline mood and arousal } \\
\text { neasures }(\mathrm{n}=18 \text { ). } \\
\text { Kruskal-Wallis } \mathrm{H} \text { (non-parametric). } \\
\text { Bonferroni post-hoc comparisons comparing all groups and separately by } \\
\text { experimental (comedy, surgery) conditions were performed to verify group } \\
\text { comparability despite non-significant ANOVAs; all comparisons were non-significant } \\
\text { ps }=.32-1.0)\end{array}$} \\
\hline
\end{tabular}

\subsubsection{Subjective arousal and mood effects}

Four participants failed to complete the post-video arousal/mood ratings (2-immediate (negative), 2-10-min group (positive)). The analysis of subjective arousal and mood response to the video stimulus was assessed using a 2 (measures, withinsubjects) $\times 2$ (tape, between-subjects) $\times 4$ (group, between-subjects) ANOVA. The results showed that arousal significantly increased from baseline across groups and type of tape $(F(1,153)=91.6, p=.0001$, $\eta^{2}=.38$ ). All other effects were non-significant ( $p s>.25$ ) except the interaction of measures and tape, which indicated a somewhat stronger effect of the surgery tape $\left(F(1,153)=6.0, p<.02, \eta^{2}=.04\right)$. When analyzed separately by type of tape, arousal was significantly 
elevated from baseline in all experimental groups with either tape valence (comedy $F(1,98)=39.6, p=.0001, \eta^{2}=.29$; surgery $\left.F(1,55)=46.3, p=.0001, \eta^{2}=.46\right)$. There were no effects of or interactions with delay group ( $p s>.32$ ). Follow-up analysis confirmed that each delay group had a significant increase in arousal from baseline, irrespective of tape (each $p<.02$; see Fig. 1).

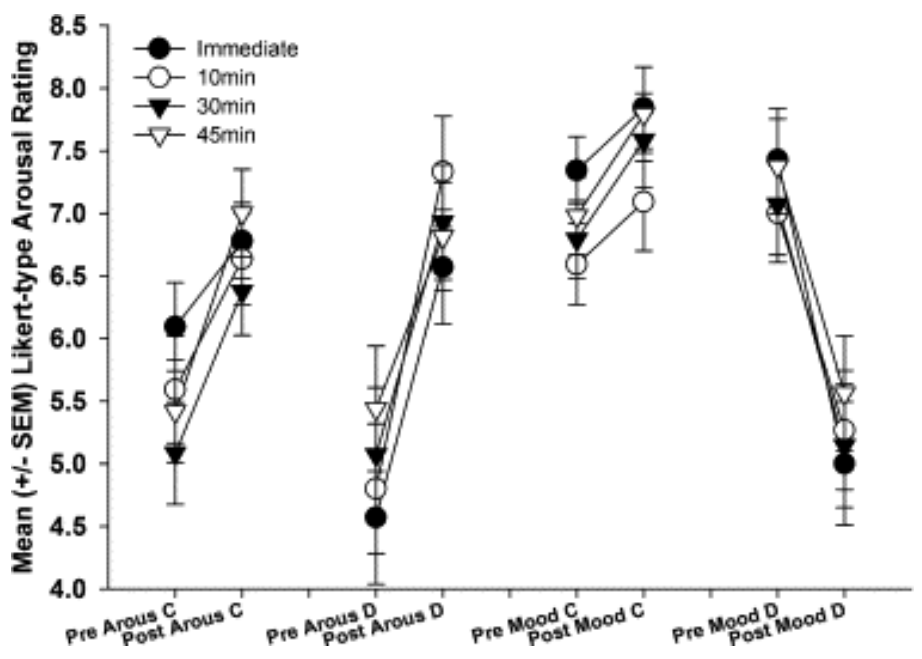

Fig. 1. Subjective arousal and mood ratings, baseline to post-video, are shown for each experimental group. The mean rating scores ( \pm SEM) are shown separately for those who saw the oral surgery video (negative arousal, "D") and those who saw the comedy video (positive arousal, "C"). All groups had significantly enhanced arousal post-video (all groups pre-post, $\mathrm{p}<.02$ ) and significantly altered mood post-video, with those who saw the positive comedy video increasing from baseline (all groups $p<.05$ ) and those who saw the negative surgery video declining from baseline (all groups $\mathrm{p}<.02$ ).

Mood also significantly changed from baseline $(F(1,153)=21.4$, $p<.0001, \eta^{2}=.12$ ), and as expected, the direction of the mood change differed by tape $\left(F(1,153)=18.5, p=.0001, \eta^{2}=.11\right.$; measures $\times$ tape interaction, $\left.F(1,153)=84.0, p=.0001, \eta^{2}=.35\right)$. The delay groups however did not differ in any comparison. When analyzed separately by tape, those who saw the comedy tape exhibited a significant increase from baseline $(F(1,98)=23.3$, $\left.p=.0001, \eta^{2}=.19\right)$, while those who saw the surgery tape exhibited a significant decrease from baseline $(F(1,55)=43.9, p=.0001$, $\left.\eta^{2}=.44\right)$. There were no differences by or interactions with delay group ( $p s>.23$ ). Follow-up analysis confirmed that each delay group had a significant change in mood from baseline, increased in comedy groups and decreased in surgery groups (each $p<.05$; see Fig. 1). 


\subsubsection{Memory}

Recognition memory for the word list tested one week after learning revealed significant arousal group differences $\left(F(4,206)=4.0, p=.004, \eta^{2}=.07\right.$; see Fig. 2$)$. Planned contrasts showed that arousal induced after learning significantly enhanced delayed retrieval as compared with Controls at all delays except 45 min (Immediate $d=4.6, p=.01 ; 10$ - $\min d=5.4, p=.004 ; 30$ $\min d=5.4, p=.005 ; 45-\min d=0.66, p=.72$ ). A full (unbalanced model) analysis, where Controls constituted a third tape condition ("no tape") showed no significant main effect of tape $(F(1,202)=0.11$, $\left.p=.75, \eta^{2}=.001\right)$ or tape $\times$ group interaction $(F(3,202)=0.21$, $\left.\mathrm{p}=.89, \eta^{2}=.003\right)$. The group main effect remained significant $\left(F(3,206)=2.9, p=.038, \eta^{2}=.04\right)$. Thus, the two tape stimuli did not differ significantly in effectiveness. When examined separately by tape group, the participants who saw the comedy video had significantly enhanced recognition versus Controls in all delay groups except $45-\min \left(F(4,145)=2.84, p=.03, \eta^{2}=.07\right.$; contrast ps <.03). The exact same pattern was found for those who saw the surgery video; arousal at all delays enhanced later retrieval except for the 45 - min delay $\left(F(4,102)=2.86, p=.027, \eta^{2}=.10\right.$; contrast ps <.03).

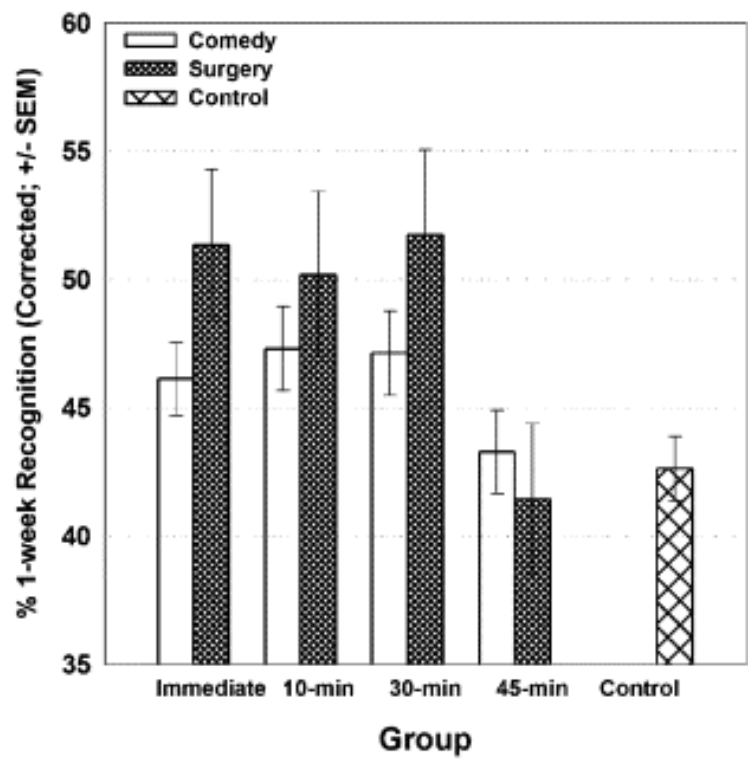

Fig. 2. The mean percentages ( \pm SEM) of words recognized, corrected for guessing, is shown for participants in each arousal condition. Arousal induced after learning by

[Neurobiology of Learning and Memory, Vol 88, No. 1 (July 2007): pg. 40-47. DOI. This article is @ Elsevier and permission has been granted for this version to appear in e-Publications@Marquette. Elsevier does not grant permission for this article to be further copied/distributed or hosted elsewhere without the express permission from Elsevier.] 
either a positive or negative stimulus significantly enhanced word retrieval after one week as compared with Controls. Delay of arousal induction up to $30 \mathrm{~min}$ after learning was effective, producing approximately $11-21 \%$ improvement in retrieval, suggesting the window of opportunity to influence memory is between 30 and 45 min.

A recent study suggested that there may be differential responses to post-training memory modulatory treatments depending on initial learning ability (Torras-Garcia et al., 1997). Thus, a post-hoc analysis was performed to examine whether there was a differential response to memory modulation for participants whose initial learning on the task was either good or poor. A median split was performed for immediate recall percentage, with Poor Learners categorized as those with median performance or less and Good Learners categorized as those above the median. Both main effects were significant, Arousal Group $\left(\mathrm{F}(4,202)=4.8, \mathrm{p}=.001, \eta^{2}=.09\right)$ and Learning Group $\left(F(1,202)=80.4, p=.0001, \eta^{2}=.29\right)$. The interaction was not significant $\left(F(4,202)=0.84, p=.50, \eta^{2}=.01\right)$. Thus, although better initial learning produced better delayed retrieval overall, initial learning did not affect response to the arousal manipulation; in both groups, the pattern of enhancement by memory modulation was comparable (see Fig. 3).

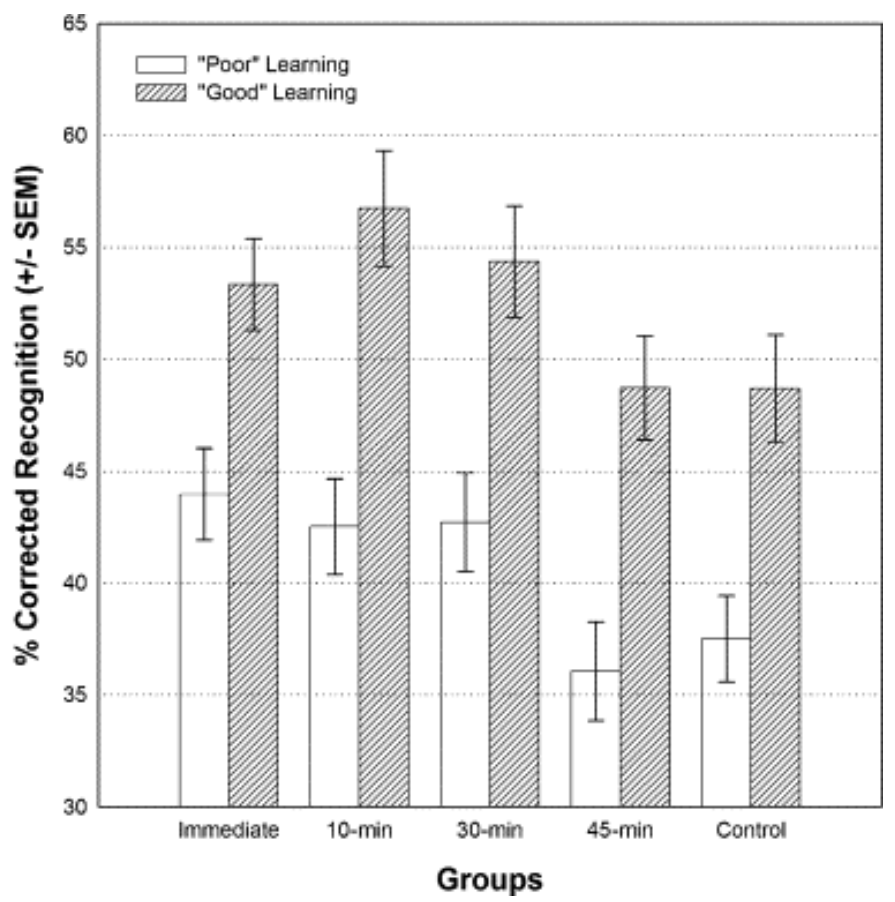

Fig. 3. The mean percentages of corrected recognition scores ( \pm SEM) is shown for participants in each arousal condition separated by initial learning group. Good initial

[Neurobiology of Learning and Memory, Vol 88, No. 1 (July 2007): pg. 40-47. DOI. This article is @ Elsevier and permission has been granted for this version to appear in e-Publications@Marquette. Elsevier does not grant permission for this article to be further copied/distributed or hosted elsewhere without the express permission from Elsevier.] 
learners had better delayed retention performance than Poor learners. But arousal after learning at delays up to 30 min was equally effective in both groups to enhance delayed recognition over Controls.

The gender distribution in this study was heavily skewed toward females, which is a common occurrence in Psychology subject pools ( females $=155$; males $=57$ (male range per cell $=9-13)$ ). However, a post-hoc analysis was performed as a preliminary assessment of whether there were any systematic gender differences in response to memory modulation because recent studies suggest they might exist (e.g., Cahill \& van Stegeren, 2003). A 5 Group $\times 2$ Gender ANCOVA for delayed recognition performance showed that in addition to the significant effect of Group $\left(F(4,201)=3.2, p=.014, \eta^{2}=.06\right)$, females outperformed males (Gender $F(1,201)=5.6, p=.019$, $\left.\eta^{2}=.03\right)$, but there was no significant interaction with the experimental manipulation (Group $\times$ Gender $F(4,201$ ) $=1.07$, $\left.p=.37, \eta^{2}=.01\right)$.

\section{Discussion}

The results clearly demonstrated that arousal induced after learning a word list, using either a positively or negatively valenced stimulus, significantly enhanced delayed memory retrieval.

Furthermore, the arousal stimulus was equally effective whether given immediately after learning or when delayed for up to $30 \mathrm{~min}$. The average difference relative to Controls was as much as $10 \%$ points, amounting to as much as $21 \%$ improvement in performance. I mportantly, delays of 45 min were not effective, supporting the nonhuman literature in indicating memory modulation is time-dependent. Because the word list and the arousal source were entirely unrelated and because the intervention occurred after learning, encoding and attention processes could not have been responsible for the effect. Additionally, subjective mood and arousal measures documented that the groups, which were all evaluated at the same time and place, were very comparable prior to manipulation and each group had measurable and comparable response to the arousal stimuli.

Few studies have empirically employed emotion or arousal to alter memory in human participants and only a small number employed post-training paradigms that can isolate the effects of the

[Neurobiology of Learning and Memory, Vol 88, No. 1 (July 2007): pg. 40-47. DOI. This article is (C) Elsevier and permission has been granted for this version to appear in e-Publications@Marquette. Elsevier does not grant permission for this article to be further copied/distributed or hosted elsewhere without the express permission from Elsevier.] 
intervention on memory consolidation rather than encoding or attention (Cahill et al., 2003; Colrain et al., 1992; Manning et al., 1992; Nielson \& Bryant, 2005; Nielson \& Jensen, 1994; Nielson et al., 1996, 2005; Southwick et al., 2002). More, negative arousal sources have almost exclusively been employed by past studies. The present findings support the existing literature and extend it by showing memory enhancement using positively arousing stimuli and showing that both positive and negative treatments have comparable effects on subjective arousal. Thus, the results suggest that arousal, rather than valence, was central to the memory modulatory effects of the emotional stimulus employed. These results and implications are consistent with recent behavioral and neuroimaging research showing that distinct cognitive and neural processes contribute to memory enhancement by arousal versus valence. Specifically, studies have shown that arousal-induced memory enhancement, mediated by an amygdalar-hippocampal network, occurs automatically (i.e., it is not affected by secondary tasks Kensinger \& Corkin, 2004) and is more associated with encoding and remembering (Hamann, 2001; Hurlemann et al., 2005), while valence, mediated by a prefrontalhippocampal network, is implicated in controlled encoding processes (Kensinger \& Corkin, 2004) and is associated with retrograde forgetting (Hamann, 2001; Hurlemann et al., 2005). Thus, modulation of memory consolidation by post-training treatments implicates arousal processes as opposed to valence of stimuli, which the current study supports.

Arousal at encoding has been postulated to interact with memory modulation effects (Cahill \& Alkire, 2003; Cahill et al., 2003). However, indirect evidence from the present study suggests that such effects are at least not necessary for memory modulation to occur. Specifically, the words used were equivalent, highly concrete and imaginable nouns and two-thirds of them had standardized arousal and valence values, which were moderate and without extreme range. Thus, there is little basis for suspecting that any of the items learned produced differential arousal or emotional responses at encoding that would make them more or less memorable. Moreover, although arousal responses were not measured physiologically in this study, there is no reason to suspect that arousal levels prior to or during the encoding task differed among the groups of participants because they all experienced the same conditions at the exact same time, only

[Neurobiology of Learning and Memory, Vol 88, No. 1 (July 2007): pg. 40-47. DOI. This article is @ Elsevier and permission has been granted for this version to appear in e-Publications@Marquette. Elsevier does not grant permission for this article to be further copied/distributed or hosted elsewhere without the express permission from Elsevier.] 
experiencing different conditions after learning. Furthermore, although the learning session lengths varied by subject group, subjective arousal and mood ratings after learning but prior to the arousal manipulation were very consistent between groups; all comparisons were non-significant. Thus, the present study suggests that at least with neutral materials, arousal during encoding is not necessary for memory modulation to occur. This further supports the idea that materials of any valence or arousal value could be enhanced by posttraining memory modulation techniques. This result is consistent with several previous studies (Colrain et al., 1992; Manning et al., 1992; Nielson \& Bryant, 2005; Nielson \& Jensen, 1994; Nielson et al., 1996, 2005) and contrasts with contentions that materials must have inherent affective or arousal quality for memory modulation to occur (e.g., Cahill et al., 2003; Libkuman, Nichols-Whitehead, Griffith, \& Thomas, 1999).

Several recent studies have indicated gender differences in the neural processing of emotional memories (Cahill et al., 2001; Canli, Desmond, Zhao, \& Gabrieli, 2002) and responsiveness to memory modulation techniques (Cahill \& van Stegeren, 2003). The present study was not designed to evaluate gender differences, having a ratio of $>3$ : 1 females. Thus, it cannot provide a definitive evaluation of this issue. However, a post-hoc analysis of gender differences showed that females outperformed males, which is a common finding for verbal episodic memory tests (e.g., Halpern, 2000; Herlitz, Nilsson, \& Bäckman, 1997; Kimura, 1999; Ruff, Light, \& Quayhagen, 1989). Moreover, we found no evidence of differential response to memory modulation via emotional stimuli between genders. Indeed, one recent study also found no effect of gender, but rather a significant effect on emotional memory scores due to sex-role identity (Cahill, Gorski, Belcher, \& Huynh, 2004).

One recent study of memory modulation by post-training epinephrine injections in rats found differential effects of the treatment depending on the initial learning performance of the rats. TorrasGarcia et al. (1997) found that rats whose performance was above the mean on the third and final acquisition trials block of an active avoidance task were impaired by an immediate post-training epinephrine injection when measured at 20- and 45-day retention tests, while rats who were below the mean at the end of acquisition

[Neurobiology of Learning and Memory, Vol 88, No. 1 (July 2007): pg. 40-47. DOI. This article is @ Elsevier and permission has been granted for this version to appear in e-Publications@Marquette. Elsevier does not grant permission for this article to be further copied/distributed or hosted elsewhere without the express permission from Elsevier.] 
were enhanced at those retention tests by the epinephrine. The present study differs in many regards from the Torras-Garcia et al. study, but an analysis of initial learning performance was warranted to evaluate the possibility of such an effect. We found that Good learners outperformed Poor learners on one-week delayed retention but no differential effect on response to post-training memory modulation response occurred. It is possible that this susceptibility differs between rats and humans, or that it is particular to tasks that involve multiple learning trials, longer delays and/or relatively high stress or arousal (as occurs in active avoidance paradigms but not in the current task).

The current findings are unique and extremely revealing about the foundations of the memory consolidation process in humans. Memory modulation studies in recent years have almost exclusively used immediate post-training manipulations because the early findings indicated that treatments were more effective when given soon after learning (cf. McGaugh, 1989, 2000). Moreover, human studies have not before addressed the effectiveness of delayed memory modulation interventions. The current findings show that a positive or negative emotional arousal source can be effective to enhance memory for at least $30 \mathrm{~min}$. The task used herein involved word-list learning, a basic episodic memory task in which the words were relatively neutral in valence and arousal. The interval and susceptibility to memory modulation might vary with the task conditions, the affective or arousal "tone" of the stimuli and intensity of modulating treatment, as has been demonstrated in the animal literature (cf. McGaugh, 1989, 2000). This possibility has not yet been studied. However, a relatively long time frame for susceptibility to modulation for the type of learning studied here is likely adaptive. It could allow the events and feelings associated in time with an experience, which are often relevant, to affect importance of the experience for long-term storage. Yet, it also reveals that feelings and events that occur for quite some time afterward, even when irrelevant to the event or information to be remembered, might significantly affect whether it is later recollected.

These results shed considerable new light on understanding of the factors that could alter remembering of factual details and events-either by enhancing, impairing or misinforming. Our findings might have implications for diverse applications. For instance, in the clinical and educational arenas the present study suggests that

[Neurobiology of Learning and Memory, Vol 88, No. 1 (July 2007): pg. 40-47. DOI. This article is @ Elsevier and permission has been granted for this version to appear in e-Publications@Marquette. Elsevier does not grant permission for this article to be further copied/distributed or hosted elsewhere without the express permission from Elsevier.] 
manipulations might be applied fairly flexibly for some time after learning. Such techniques could be particularly useful in classroom environments where flexibility over how and when to administer memory enhancing treatments is essential. More, most memory interventions employ techniques that alter the learning environment or the learner's strategies. The present results support the idea that memory enhancements can be effective without altering learning per se. Studies designed to assess these possibilities are currently under way.

These results might also have important implications for forensic work. Although emotion and arousal likely play important roles in encoding and attention for an event, the present results raise the possibility that the memory of a witness to an accident or a crime might be affected beneficially or detrimentally for quite some time after the event in question. Thus, protecting the veridical accounts of witnesses, and demonstrating their validity, may require careful scrutiny of the environment and emotional state of the witness for a fairly lengthy time after the events in question have ended. Moreover, the findings suggest that memory intervention strategies could possibly be intentionally employed to safeguard a witness' memory from interference. These and other potential applications will require clearly careful study, possibility that episodic memory might be malleable for such a long period after formation makes such studies essential.

\section{Acknowledgments}

We gratefully acknowledge the assistance of Vasilios Bournas, Caroline Freitag, Jason Galloway, Patrick Gunderson, Jessica Nilles, Maria Provias, Clare Tyson and Maureen Schrock. This work was supported by a Summer Faculty Fellowship and a Sabbatical Fellowship from Marquette University (KAN).

\section{References}

Bradley and Lang, 1999

Bradley, M.M., \& Lang, P.J . (1999). Affective norms for english words (anew): instruction manual and affective ratings (Technical Report C1). Gainsville, FL: The Center for Research in Psychophysiology, University of Florida.

[Neurobiology of Learning and Memory, Vol 88, No. 1 (July 2007): pg. 40-47. DOI. This article is (c) Elsevier and permission has been granted for this version to appear in e-Publications@Marquette. Elsevier does not grant permission for this article to be further copied/distributed or hosted elsewhere without the express permission from Elsevier.] 
NOT THE PUBLISHED VERSION; this is the author's final, peer-reviewed manuscript. The published version may be accessed by following the link in the citation at the bottom of the page.

Cahill and Alkire, 2003

L. Cahill, M.T. Alkire. Epinephrine enhancement of human memory consolidation: interaction with arousal at encoding. Neurobiology of Learning and Memory, 79 (2) (2003), pp. 194-198

Cahill et al., 2004

L. Cahill, L. Gorski, A. Belcher, Q. Huynh. The influence of sex versus sex-related traits on long-term memory for gist and detail from an emotional story. Consciousness and Cognition, 13 (2004), pp. 391-400

Cahill et al., 2003

L. Cahill, L. Gorski, K. Le. Enhanced human memory consolidation with post-learning stress: interaction with the degree of arousal at encoding. Learning and Memory, 10 (4) (2003), pp. 270-274

Cahill et al., 2001

L. Cahill, R. Haier, N.S. White, J. Fallon, L. Kilpatrick, C. Lawrence, et al. Sex difference in amygdala activity during emotionally influenced memory storage. Neurobiology of Learning and Memory, 75 (2001), pp. 1-9

Cahill and van Stegeren, 2003

L. Cahill, A. van Stegeren. Sex-related impairment of memory for emotional events with beta-adrenergic blockade. Neurobiology of Learning and Memory, 79 (1) (2003), pp. 81-88

Canli et al., 2002

T. Canli, J. Desmond, Z. Zhao, J.D.E. Gabrieli. Sex differences in the neural basis of emotional memories. Proceedings of the National Academy of Sciences of the United States of America, 99 (2002), pp. 10789-10794

Colrain et al., 1992

I.M. Colrain, G.L. Mangan, O.L. Pellett, T.C. Bates. Effects of postlearning smoking on memory consolidation. Psychopharmacology, 108 (1992), pp. 448-451

Gavanski, 1986

I. Gavanski. Differential sensitivity of humor ratings and mirth responses to cognitive and affective components of the humor response. Journal of Personality and Social Psychology, 51 (1) (1986), pp. 209-214

Gold, 2005

P.E. Gold. Glucose and age-related changes in memory. Neurobiology of Aging, 26 (Suppl. 1) (2005), pp. 60-64

Halpern, 2000

D.F. Halpern. Sex differences in cognitive abilities (3rd ed.), Lawrence Erlbaum Associates, Inc, Mahwah, NJ (2000)

[Neurobiology of Learning and Memory, Vol 88, No. 1 (July 2007): pg. 40-47. DOI. This article is @ Elsevier and permission has been granted for this version to appear in e-Publications@Marquette. Elsevier does not grant permission for this article to be further copied/distributed or hosted elsewhere without the express permission from Elsevier.] 
NOT THE PUBLISHED VERSION; this is the author's final, peer-reviewed manuscript. The published version may be accessed by following the link in the citation at the bottom of the page.

Hamann, 2001

S. Hamann. Cognitive and neural mechanisms of emotional memory. Trends in Cognitive Sciences, 5 (9) (2001), pp. 394-400

Herlitz et al., 1997

A. Herlitz, L.-G. Nilsson, L.G. Bäckman. Gender differences in episodic memory. Memory and Cognition, 25 (1997), pp. 801-811

Hurlemann et al., 2005

R. Hurlemann, B. Hawallek, A. Matusch, H. Kolsch, H. Wollersen, B. Madea, et al. Noradrenergic modulation of emotion-induced forgetting and remembering. J ournal of Neuroscience, 25 (27) (2005), pp. 63436349

Kensinger and Corkin, 2004

E. A. Kensinger, S. Corkin. Two routes to emotional memory: distinct neural processes for valence and arousal. Proceedings of the National Academy of Sciences of the United States of America, 101 (9) (2004), pp. 3310-3315

Kimura, 1999

D. Kimura. Sex and cognition, MIT Press, Cambridge, MA (1999)

Libkuman et al., 1999

T.M. Libkuman, P. Nichols-Whitehead, J. Griffith, R. Thomas. Source of arousal and memory for detail. Memory and Cognition, 27 (1) (1999), pp. 166-190

Manning et al., 1992

C.A. Manning, M. Parsons, P.E. Gold. Anterograde and retrograde enhancement of 24-h memory by glucose in elderly humans.

Behavioral and Neural Biology, 58 (1992), pp. 125-130

McGaugh, 1989

J.L. McGaugh. Modulation of memory storage processes. P.R. Soloman, G.R. Goethals, C.M. Kelley, B.R. Stephens (Eds.), Memory: Interdisciplinary approaches, Springer-Verlag, New York (1989), pp. 33-64

McGaugh, 2000

J.L. McGaugh. Memory-a century of consolidation. Science, 287 (14 January) (2000), pp. 248-251

McGaugh et al., 1996

J.L. McGaugh, L. Cahill, B. Roozendaal. Involvement of the amygdala in memory storage: interaction with other brain systems. Proceedings of the National Academy of Sciences of the United States of America, 93 (1996), pp. 13508-13514

Müller and Pilzecker, 1900

G.E. Müller, A. Pilzecker. Experimentelle beitrage zur lehre vom gedachtnis [Experimental contributions in learning and memory]. Zeitschrift für Psychologie Erganzungsband, 1 (1900), pp. 1-288

[Neurobiology of Learning and Memory, Vol 88, No. 1 (July 2007): pg. 40-47. DOI. This article is @ Elsevier and permission has been granted for this version to appear in e-Publications@Marquette. Elsevier does not grant permission for this article to be further copied/distributed or hosted elsewhere without the express permission from Elsevier.] 
NOT THE PUBLISHED VERSION; this is the author's final, peer-reviewed manuscript. The published version may be accessed by following the link in the citation at the bottom of the page.

Nielson and Bryant, 2005

K.A. Nielson, T. Bryant. The effects of non-contingent extrinsic and intrinsic rewards on memory consolidation. Neurobiology of Learning and Memory, 84 (2005), pp. 42-48

Nielson and J ensen, 1994

K.A. Nielson, R.A. Jensen. Beta-adrenergic receptor antagonist antihypertensive medications impair arousal-induced modulation of working memory in elderly humans. Behavioral and Neural Biology, 62 (1994), pp. 190-200

Nielson et al., 1996

K.A. Nielson, R.C. Radtke, R.A. Jensen. Arousal-induced modulation of memory storage processes in humans. Neurobiology of Learning and Memory, 66 (1996), pp. 133-142

Nielson et al., 2005

K.A. Nielson, D. Yee, K.I. Erickson. Memory enhancement by a semantically unrelated emotional arousal source induced after learning. Neurobiology of Learning and Memory, 84 (2005), pp. 49-56

Paivio et al., 1968

A. Paivio, J.C. Yuille, S.A. Madigan. Concreteness, imagery, and meaningfulness values for 925 nouns. J ournal of Experimental Psychology, 76 (Suppl.) (1968), pp. 1-25

Revelle and Loftus, 1992

W. Revelle, D.A. Loftus. The implications of arousal effects for the study of affect and memory. S. Christianson (Ed.), The handbook of emotion and memory, Lawrence Erlbaum Associates, Hillsdale (1992), pp. 113-150

Ruff et al., 1989

R.M. Ruff, R.H. Light, M. Quayhagen. Selective reminding tests: a normative study of verbal learning in adults. Journal of Clinical and Experimental Neuropsychology, 11 (1989), pp. 539-550

Southwick et al., 2002

S.M. Southwick, M. Davis, B. Horner, L. Cahill, C.A. Morgan, P.E. Gold, et al. Relationship of enhanced norephinphrine activity during memory consolidation to enhanced long-term memory in humans. American Journal of Psychiatry, 159 (2002), pp. 1420-1422

Stone and Nielson, 2001

L.A. Stone, K.A. Nielson. Physiological response to arousal and impaired emotional expression in alexithymia. Psychotherapy and Psychosomatics, 70 (2001), pp. 92-102

Torras-Garcia et al., 1997 M. Torras-Garcia, I. Portell-Cortes, D. Costa-Miserachs, I. MorgadoBernal. Long-term memory modulation by posttraining epinephrine in

[Neurobiology of Learning and Memory, Vol 88, No. 1 (July 2007): pg. 40-47. DOI. This article is (C) Elsevier and permission has been granted for this version to appear in e-Publications@Marquette. Elsevier does not grant permission for this article to be further copied/distributed or hosted elsewhere without the express permission from Elsevier. 
NOT THE PUBLISHED VERSION; this is the author's final, peer-reviewed manuscript. The published version may be accessed by following the link in the citation at the bottom of the page.

rats differential effects depending on the basic learning capacity.

Behavioral Neuroscience, 111 (1997), pp. 301-308

Yerkes and Dodson, 1908

R. Yerkes, J. Dodson. The relation of strength of stimulus to rapidity of habit-formation. Journal of Comparative Neurology and Psychology, 18 (1908), pp. 459-482

[Neurobiology of Learning and Memory, Vol 88, No. 1 (July 2007): pg. 40-47. DOI. This article is @ Elsevier and permission has been granted for this version to appear in e-Publications@Marquette. Elsevier does not grant permission for this article to be further copied/distributed or hosted elsewhere without the express permission from Elsevier.] 